\title{
Família, Gênero e Orientação Sexual: questões enfrentadas pelo Papa Francisco
}

Luís Corrêa Lima'

\section{Introdução}

As transformações na família nas últimas décadas, com a emergência de novas configurações e a visibilidade de novos sujeitos, são um desafio para a Igreja Católica e sua missão de evangelizar. O Papa Francisco convocou o Sínodo dos Bispos voltado para este tema, lançando na Igreja um amplo debate, e depois publicou a Exortação Pós-sinodal Amoris Laetitia sobre o amor na família. Questões de gênero, orientação sexual e união homossexual tem sido foco de conflitos entre religiosos e outros segmentos da sociedade, incidindo no Estado e nas políticas públicas. Entretanto, muitas ideias surgidas no contexto do Sínodo, bem como alguns pontos da Exortação, contribuem consideravelmente para se abrir novos caminhos.

O papa Francisco marca o seu pontificado pelo firme propósito de renovação pastoral na Igreja Católica, convocando-a a ir às periferias existenciais, ao encontro dos que sofrem com as diversas formas de injustiças, conflitos e carências. Ele critica uma Igreja ensimesmada, entrincheirada em "estruturas caducas incapazes de acolhimento" e fechada aos novos caminhos que Deus Ihe apresenta (FRANCISCO, 2013a). Estas periferias existenciais inegavelmente abrangem também os LGBT (gays, lésbicas, bissexuais, travestis e transexuais), que constituem uma população com crescente visibilidade. Na sua viagem do Brasil a Roma, o papa disse algo que teve muita repercussão: "Se uma pessoa é gay, procura o Senhor e tem boa vontade, quem sou eu para julgá-la? [...] Não se devem marginalizar estas pessoas por isso" (FRANCISCO, 2013b). Tal declaração foi inédita na boca de um pontífice e abriu novas perspectivas.

Convém esclarecer alguns termos sobre este assunto, sem esgotar a notável complexidade. Travestis são pessoas que vivenciam papéis femininos, mas não se reconhecem como homens ou como mulheres. Transexuais são pessoas que não se identificam com o sexo que lhes é atribuído ao nascerem, mas sim com o outro sexo. Pode haver homem transexual, que reivindica o reconhecimento social e legal como homem, e mulher transexual, que reivindica o reconhecimento social e legal como mulher (JESUS, 2012, p. 5-18). A visibilidade dos LGBT é um dos sinais mais notáveis do mundo atual. No passado, para se defenderem da intolerância e da hostilidade da qual eram alvo, muitos deles viviam no anonimato ou à margem da sociedade. Vários

\footnotetext{
${ }^{1}$ Padre jesuíta, historiador e professor do Departamento de Teologia da PUC-Rio.
} 
gays e lésbicas se escondiam no casamento tradicional, constituído pela união heterossexual, para não manifestarem a sua condição. Mas hoje muitos LGBT fazem grandes paradas, estão presentes em filmes, programas de televisão, olimpíadas, empresas, escolas e outras instituições; buscam reconhecimento, exigem ser respeitados e reivindicam os mesmos direitos e deveres dos demais cidadãos. Esta população está em toda parte. Quem não faz parte dela, tem parentes próximos ou distantes que fazem, velada ou manifestamente, bem como vizinhos ou colegas de trabalho.

A visibilidade desta população também expõe os problemas que a afligem. Em muitos países, há uma aversão a homossexuais, a homofobia; e a travestis e transexuais, a transfobia. Tal aversão produz diversas formas de violência física, verbal e simbólica contra estas pessoas. Há pais de família que já disseram: "prefiro um filho morto a um filho gay". Não são raros travestis, gays e lésbicas expulsos de casa por seus pais. Entre os palavrões mais ofensivos que existem em português, constam a referência à condição homossexual e a referência ao sexo anal, comum no homoerotismo masculino. Ou seja, é xingamento. Muitas vezes, quando se diz que fulano não é "homem", entende-se que é gay; ou fulana não é "mulher", que é lésbica. Ou seja, ser homem ou mulher supostamente exclui a pessoa homossexual. A homofobia e a transfobia se enraízam profundamente na cultura. No Brasil são frequentes os homicídios, sobretudo de travestis. Há também suicídios de muitos adolescentes que se descobrem gays ou lésbicas, e mesmo de adultos. Eles chegam a esta atitude extrema por pressentirem a rejeição hostil da própria família e da sociedade. Tal hostilidade gera inúmeras formas de discriminação e, mesmo que não leve à morte, traz frequentemente tristeza profunda ou depressão.

\section{O Sínodo dos Bispos sobre a família e a Amoris Laetitia}

Já no primeiro ano do pontificado de Francisco, em 2013, foi convocado o Sínodo dos Bispos para tratar da família e seus desafios atuais, dando início a um período rico e criativo. A mensagem cristã no campo da sexualidade e da família tem uma grandeza e uma beleza inegáveis, mas também problemas e questionamentos inevitáveis. Em certos pontos, há uma notável disparidade entre o ensinamento da Igreja e a vida da maioria dos fiéis.

No questionário preparatório do Sínodo, enviado a todas as dioceses católicas do mundo, perguntava-se, entre outras coisas, que atenção pastoral se pode dar às pessoas que escolheram viver em uniões do mesmo sexo e, caso adotem crianças, o que fazer para lhes transmitir a fé. Ocorreram muitos debates e entrevistas, produziramse amplos relatórios, com uma notável repercussão na mídia. O Sínodo é uma 
instituição consultiva, bem como os seus relatórios e proposições. Após a sua realização, o papa publica uma exortação pós-sinodal, que é o ensinamento oficial (magistério) da Igreja a respeito do tema tratado. Neste caso, é o documento Amoris Laetitia $(A L)$ sobre o amor na família.

Mesmo sendo apenas consultivo, o Sínodo traz indicações bastante relevantes sobre a situação eclesial, os consensos e as divergências existentes entre os bispos, que são muito importantes para o discernimento do papa. Os relatórios produzidos desde a convocação deste Sínodo apontaram claramente nesta direção: não mudar a doutrina da Igreja sobre a família, fundada na união exclusiva e indissolúvel entre um homem e uma mulher, mas ao mesmo tempo acolher sem condenar as pessoas que vivem em outras configurações familiares. O valor deste processo, além dos textos normativos, é o debate aberto na Igreja sobre questões de sexualidade, família, gênero e bioética como nunca se viu nas últimas décadas. Isto ajuda a formar e a expressar consensos dos fiéis, favorecendo a pastoral, a reflexão teológica e a recepção criativa da Exortação Pós-sinodal, que neste caso de certo modo incidem na relação entre igreja e Estado, e nas políticas públicas.

Certa vez, Francisco declarou que o conhecimento da verdade é progressivo. A compreensão do ser humano muda com o tempo, e sua consciência se aprofunda. Recorde-se a época em que a escravatura era aceita e a pena de morte era admitida sem nenhum problema. Os exegetas e os teólogos, como também as outras ciências e a sua evolução, ajudam a lgreja a amadurecer o próprio juízo. Como consequência, há normas e preceitos eclesiais secundários que em outros tempos foram eficazes, mas que hoje perderam valor ou significado. E conclui que uma visão da doutrina da Igreja como um bloco monolítico a ser defendido sem matizes é errada (FRANCISCO, 2013c). Isto retoma o ensinamento do Concílio Vaticano II, exortando que na atividade pastoral se conheçam e se apliquem suficientemente não apenas os princípios teológicos, mas também os dados das ciências profanas, principalmente da psicologia e da sociologia, para que os fiéis sejam conduzidos a uma vida de fé mais pura e adulta (GS, 1965, n. 62). O processo sinodal ajuda a Igreja neste conhecimento progressivo da verdade, bem como na busca de caminhos pastorais adequados.

As exortações pós-sinodais, incluindo a Amoris Laetitia, são elaboradas a partir dos consensos alcançados nas assembleias sinodais. O magistério da lgreja em nível universal deve levar em conta os diferentes contextos de Continentes e países. A tarefa de articular convergências e chegar a um denominador comum é complexa e nada fácil. A evolução das ciências, a teologia e o discernimento dos fiéis ajudam efetivamente a Igreja a amadurecer seu juízo, mas isto leva tempo e este amadurecimento não é homogêneo. Porém, as igrejas locais, suas iniciativas apostólicas e a reflexão teológica 
podem avançar mais, criando um ambiente eclesial favorável a mudanças futuras de maior alcance. As conferências episcopais trazem contribuições importantes à inculturação e à pastoral, que são fruto de reflexões e práticas contextualizadas em diferentes realidades, com suas tradições e desafios.

A Exortação do papa sobre a família foi assinada no dia de São José (19/3/2016), que na liturgia católica é patrono da Sagrada Família, composta por Jesus, Maria e José. Amoris Laetitia é uma ampla dissertação, partindo da premissa de que a alegria do amor vivido nas famílias é também o júbilo da Igreja. A força da família reside essencialmente na sua capacidade de amar e ensinar a amar ( $A L 1$ e 53). Muitas situações e questões contemporâneas são contempladas, lançando luzes sobre a vida familiar concreta. A Exortação está longe de ser um texto doutrinário abstrato e frio. A grande novidade está na forte sensibilidade pastoral, com matizes muito cuidadosos na aplicação da doutrina. Para o papa, nem todas as discussões doutrinais, morais e pastorais devem ser resolvidas com intervenção do magistério. Naturalmente, é necessária na Igreja uma unidade de doutrina e práxis, mas isto não impede que haja diferentes maneiras de interpretar alguns aspectos da doutrina ou algumas consequências que dela decorrem. Em cada país ou região, pode-se buscar soluções mais inculturadas, atentas às tradições e aos desafios locais $(A L 3)$.

Francisco faz um forte alerta contra o moralismo, que muitas vezes reina em ambientes cristãos e na hierarquia da Igreja Católica, visando fomentar o devido respeito à consciência e à autonomia dos fiéis:

“[...] nos custa dar espaço à consciência dos fiéis, que muitas vezes respondem o melhor que podem ao Evangelho no meio dos seus limites, e são capazes de realizar o seu próprio discernimento perante situações onde se rompem todos os esquemas. Somos chamados a formar as consciências, não a pretender substituí-las" ( $A L 37)$.

Nesta mesma linha, a formação moral das novas gerações deve se realizar de forma indutiva, de modo que um filho e uma filha possam chegar a descobrir por si mesmos a importância de determinados valores, princípios e normas, em vez de impôlos como verdades indiscutíveis ( $A L 264)$.

Em toda e qualquer circunstância, perante quem tenha dificuldade de viver plenamente a lei de Deus, deve ressoar o convite para percorrer a via caritatis, o caminho do amor. A caridade fraterna é a primeira lei dos cristãos, conforme o mandamento de Jesus: "amai-vos uns aos outros, como eu vos amo" (Jo 15,12). O amor constitui a plenitude da lei (Gal 5,14). Sem diminuir o ideal evangélico, deve-se acompanhar com misericórdia e paciência as possíveis etapas de crescimento das pessoas, que se constroem dia a dia. A misericórdia do Senhor nos incentiva a praticar 
o bem possível ( $A L 306$ e 308). É preciso abrir o coração aos que vivem nas mais variadas periferias existenciais. Os pastores são convidados a escutar com carinho e serenidade, com o desejo sincero de entrar no âmago do drama das pessoas e compreender o seu ponto de vista, para ajudá-las a viver melhor e reconhecer o seu lugar na Igreja ( $A L 312)$,

Não se pode dizer que todos os que estão numa situação chamada "irregular" vivem em estado de pecado mortal, privados da graça santificante. Um pastor não pode estar satisfeito apenas com a aplicação da lei moral aos que vivem nesta situação, como se fossem pedras atiradas contra a vida das pessoas. Por causa de condicionamentos ou de fatores atenuantes, pode-se viver na graça de Deus, amar e também crescer na vida da graça e da caridade, recebendo para isso a ajuda da Igreja que inclui os sacramentos. Por isso, deve-se lembrar aos sacerdotes que o confessionário, onde comumente se ministra o sacramento da penitência, não é uma sala de tortura, mas o lugar da misericórdia do Senhor. E a Eucaristia não é um prêmio para os perfeitos, mas um remédio generoso e um alimento aos que necessitam ( $A L 301,305$ e nota 351).

A questão do acesso aos sacramentos dos que vivem em situação "irregular", sobretudo os divorciados recasados, foi bastante polêmica desde a convocação do Sínodo. Há décadas que fiéis, pastores e teólogos buscam soluções para isto. O papa não dá uma solução taxativa e abrangente, mas abre caminho aos pastores para que, no acompanhamento dos fiéis e no respeito ao seu discernimento, possam ministrar-Ihes os sacramentos. As considerações sobre os fiéis em situação "irregular" se aplicam também aos que vivem em outras configurações familiares, como pais não casados e uniões homoafetivas.

\section{Gênero, orientação sexual e união homossexual}

Os estudos de gênero foram um assunto tratado pela Cúria Romana nas últimas décadas, que manifestou uma posição negativa a seu respeito, bem como do ativismo que deles decorre (LIMA, 2015, p. 91-94). Isto levou a uma divergência na Organização das Nações Unidas em 2008, quando a França propôs a descriminalização da homossexualidade em todo o mundo. A proposta francesa incluía o fim da discriminação por orientação sexual e identidade de gênero. A delegação da Santa Sé na ONU manifestou apreço pela proposta francesa de condenar todas as formas de violência contra pessoas homossexuais, e exortou os Estados, inclusive os muçulmanos, a tomarem as medidas necessárias para pôr fim a todas as penas criminais contra elas (Intervenção..., 2008). Para a Igreja Católica, baseando-se em uma "sã laicidade" do Estado, as relações sexuais livremente consentidas entre pessoas adultas não devem ser consideradas delito pelo poder civil. Mas o fim da discriminação por identidade de 
gênero e orientação sexual não foi aceito. Alegou-se que isto poderia se tornar um instrumento de pressão contra os que consideram o comportamento homossexual moralmente inaceitável, não reconhecem a união homossexual como família, nem a sua equiparação à união heterossexual e nem o seu direito à adoção e à reprodução assistida (L'Osservatore, 2008).

No Sínodo, estas questões vieram à tona manifestando divergências na assembleia. Mas algumas proposições sobre gênero alcançaram dois terços dos votos e foram incorporadas integralmente na Amoris Laetitia. Alertou-se contra "formas de uma ideologia" chamada gender (gênero). Estas negam "a diferença e a reciprocidade natural" entre homem e mulher, preveem uma sociedade sem diferença de sexo, e promovem uma identidade pessoal e uma intimidade afetiva "desvinculadas da diversidade biológica" entre homem e mulher. A identidade humana fica à mercê de uma "opção individualista". O sexo biológico (sex) e função sociocultural do sexo (gender) podem se distinguir, mas não se separar ( $A L 56)$.

As questões da homossexualidade, por sua vez, são colocadas lembrando que a Igreja deve assumir o comportamento de Jesus. Ele se oferece por todos sem exceção, com um amor sem fronteiras. Às famílias que têm filhos homossexuais, reafirma-se que cada pessoa, independentemente da própria "orientação sexual", deve ser acolhida e respeitada na sua dignidade, evitando-se toda discriminação injusta, agressão e violência. Um respeitoso acompanhamento deve ser assegurado, para que todos os que manifestam a tendência homossexual disponham da ajuda necessária para compreender e realizar plenamente a vontade de Deus em sua vida ( $A L 250)$. A acolhida de pessoas homossexuais, já ensinada no Catecismo da Igreja Católica (1992, n. 3528), é trazida para o contexto das famílias com filhos homossexuais, onde isto é mais urgente. Porém, não se aceita a equiparação das uniões homossexuais ao matrimônio, por não haver comparação entre tais uniões e o desígnio divino sobre o matrimônio e a família. Não se aceita também que haja pressão de organismos internacionais, condicionando a ajuda financeira a países pobres à introdução de leis neste sentido ( $A L 251)$.

\section{Aprofundar questões}

O alerta sobre a ideologia de gênero remete aos estudos de gênero e ao ativismo que neles se baseia. Tais estudos evidenciam o papel da cultura e das estruturas sociais na configuração e na relação entre os gêneros, questionam a subalternidade de um gênero a outro e, nas últimas décadas, contemplam a realidade de pessoas LGBT. Em inglês, este conjunto de reflexões é conhecido como gender theory, traduzido como teoria de gênero. Mas neste caso teoria não é uma tradução apropriada porque estas 
reflexões são bastante heterogêneas. Não há uma explicação unificadora e abrangente. O que há é um acordo geral em considerar os complexos comportamentos, direta ou indiretamente ligados à esfera sexual, como fruto de dimensões diferentes, não totalmente independentes e, por sua vez, complexas: o sexo anatômico, o reconhecimento de si, o papel de gênero e a orientação sexual. Não há uma coerência necessária entre o sexo atribuído ao nascer, o reconhecimento e a vivência da própria identidade como homem ou mulher, o desejo e a prática sexuais (LIMA, 2015, p. 106).

Há pesquisas de neurociência concluindo que o sexo biológico não se reduz à genitália e à anatomia. É o cérebro que define a identidade e a orientação sexual. No caso de pessoas transgênero - que não se identificam com o sexo que lhes é atribuído ao nascerem - o cérebro e a percepção de si não correspondem à genitália e ao restante do corpo. A pessoa se sente homem em um corpo de mulher, ou se sente mulher ou travesti em um corpo de homem. Com relação à orientação sexual, há odores ligados à masculinidade e à feminilidade, os feromônios, que quando inalados são identificados pelo cérebro e influem na percepção e no comportamento. No mundo animal, estes odores são fundamentais na aproximação entre os sexos e no acasalamento. Tomografias especializadas revelam que o cérebro de mulheres homossexuais responde aos feromônios de forma diferente do cérebro de mulheres heterossexuais, e de forma similar ao de homens heterossexuais. Experimentos semelhantes com homens homossexuais chagaram a resultados opostos e simétricos (HERCULANOHOUZEL, 2006, p. 46-51). Mesmo que haja também fatores psicossociais incidindo nesta realidade, ser LGBT não é uma escolha e nem uma opção individualista. São faces da complexa diversidade entre homem e mulher.

Não se pode querer que todos vivam como se fossem heterossexuais e cisgêneros (identificados com o sexo que lhes é atribuído ao nascer). Não se pode ignorar as diversas formas de discriminação e violência que oprimem e devastam a população LGBT. A filósofa Judith Butler afirma que não é necessário imaginar um futuro onde a norma binária - em que homem e mulher são necessariamente heterossexuais e cisgênero - tenha se diluído porque isto de alguma maneira já aconteceu. O desafio para ela é encontrar um melhor vocabulário para maneiras de viver o gênero e a sexualidade que não se encaixe tão facilmente na norma binária. É preciso emitir a palavra em que a complexidade existente possa ser reconhecida, onde o medo da marginalização, da patologização e da violência seja radicalmente eliminado. $E$ arrisca dizer que talvez não seja tão importante produzir novas formulações de gênero, mas sim construir um mundo em que as pessoas possam viver e respirar dentro da sua própria sexualidade e do seu próprio gênero (Judith BUTLER, 2009). Portanto, não se 
trata do fim de homens e mulheres heterossexuais e cisgênero, nem das instituições que eles e elas formam.

Há uma perspectiva cristã de gênero propondo não renunciar à diferença entre homem e mulher e à sua fundamental importância, que tem raiz no sexo anatômico e constitui o arquétipo do qual se origina a humanidade. Que não se pense nos processos sociais e culturais prescindindo inteiramente do componente biológico, da estrutura genética e neuronal do sujeito humano. Todavia, que se evidencie também o papel da cultura e das estruturas sociais, reconhecendo-se o mérito dos estudos de gênero em captar a relevância das vivências pessoais na definição da identidade de gênero. Isso contribui para a superação de preconceitos causadores de graves discriminações, que levaram e ainda levam à marginalização dos LGBT (PIANA, 2014).

\section{5. descortinar novos caminhos}

Para uma sã laicidade do Estado, que é valor para a Igreja Católica, convém explicitar do que se trata nas atuais proibições de discriminação por orientação sexual e identidade de gênero. No Rio de Janeiro, por exemplo, muitos estabelecimentos comerciais têm uma placa, em português e em inglês, dizendo que é proibido este tipo de discriminação, sob forma de constrangimentos ou atendimento diferenciado, conforme a lei municipal. Em São Paulo, uma lei estadual determina a punição de toda manifestação atentatória ou discriminatória praticada contra cidadão homossexual, bissexual ou transgênero. Uma resolução do governo federal regulamenta a inclusão dos itens "orientação sexual", "identidade de gênero" e "nome social" nos boletins de ocorrência emitidos pelas autoridades policiais no Brasil. E se considera nome social aquele pelo qual travestis e transexuais se identificam e são identificados pela sociedade. A razão apresentada é a necessidade de dar visibilidade aos crimes violentos contra a população LGBT (Resolução, 2014), e assim favorecer ações e políticas públicas para o seu devido enfrentamento. Portanto, tal legislação não é um instrumento de pressão contra o direito das igrejas de ensinarem sobre sexualidade, matrimônio e família, mas é uma maneira de defender pessoas que não raramente são humilhadas, hostilizadas e até massacradas. Não cabe aqui a acusação de ideologia de gênero.

Algumas perguntas do questionário de preparação do Sínodo não foram respondidas na Amoris Laetitia: que atenção pastoral dar às pessoas que vivem em uniões do mesmo sexo? Caso tenham crianças, o que fazer para lhes transmitir a fé? Isto é compreensível, dada a dificuldade de se chegar a consensos sobre matéria controversa em uma assembleia tão heterogênea como a do Sínodo. Mas algumas conferências episcopais dão respostas muito oportunas a estas questões. 
Os bispos franceses, em 2012, posicionaram-se diante do Projeto de Lei Matrimônio para Todos, que equipara plenamente a união homossexual à união heterossexual. Eles reafirmam a doutrina da Igreja sobre este tema, opondo-se ao Projeto. Mas não só. Repudiam a homofobia e felicitam a evolução do direito, que hoje condena toda discriminação e incitação ao ódio em razão da orientação sexual. Reconhecem que muitas vezes não é fácil para a pessoa homossexual assumir sua condição, pois os preconceitos são duradouros e as mentalidades só mudam lentamente, inclusive nas comunidades e nas famílias católicas. Estas são chamadas a acolher toda a pessoa como filha de Deus, qualquer que seja a sua situação. E numa união durável entre pessoas do mesmo sexo, para além do aspecto meramente sexual, a Igreja estima o valor da solidariedade, da ligação sincera, da atenção e do cuidado com o outro (CEF, 2012). Assim, os bispos franceses contribuem para uma sociedade e uma Igreja mais inclusivas, que reconhecem também valores positivos em uniões homoafetivas.

A CNBB tratou destas questões ao propor a renovação pastoral das paróquias, levando em conta as novas situações familiares. Os bispos brasileiros reconhecem que nas paróquias participam pessoas unidas sem o vínculo sacramental e outras em segunda união. Há também as que vivem sozinhas sustentando os filhos, avós que criam netos e tios que sustentam sobrinhos. Há crianças adotadas por pessoas solteiras ou do mesmo sexo, que vivem em união estável. Os bispos exortam a Igreja, família de Cristo, a acolher com amor todos os seus filhos. Conservando o ensinamento cristão sobre a família, é necessário usar de misericórdia. Constata-se que muitos se afastaram e continuam se afastando das comunidades porque se sentiram rejeitados, porque a primeira orientação que receberam consistia em proibições e não em viver a fé em meio à dificuldade. Na renovação paroquial, deve haver conversão pastoral para não se esvaziar a Boa Nova anunciada pela Igreja e, ao mesmo tempo, não deixar de se atender às novas situações da vida familiar. "Acolher, orientar e incluir" nas comunidades os que vivem em outras configurações familiares são desafios inadiáveis (CNBB, 2014, n-217-218). Um resultado concreto deste acolhimento é o batismo de filhos de uniões do mesmo sexo, que se torna cada vez mais comum.

Os gestos públicos do papa Francisco também contribuem para abrir novos caminhos. No início de 2015, ele recebeu em sua casa a visita do transexual espanhol Diego Neria e de sua companheira Macarena. A história de vida de Diego tornou-se então conhecida, mostrando o preconceito atroz que muitos transexuais sofrem, bem como o seu enfrentamento (HERNÁNDEZ, 2015). Outros encontros semelhantes ocorreram, como a visita a um presídio na Itália em que Francisco teve uma refeição na companhia de presos transexuais em sua mesa. Nos Estados Unidos, ele recebeu na 
nunciatura apostólica o seu antigo aluno e amigo gay Yayo Grassi, e o companheiro dele. Grassi já tinha apresentado o seu companheiro ao papa dois anos antes. Este relacionamento nunca foi problema na amizade entre Grassi e Francisco. Tais exemplos valem mais que mil palavras. Se todos os pais e familiares de LGBT seguissem o exemplo do papa, recebendo-os em suas casas com seus respectivos companheiros, vários problemas desta população seriam resolvidos. Certa vez um jornalista perguntou a Francisco o que ele diria a uma pessoa transgênero, e se ele como pastor e ministro a acompanharia. O papa respondeu que tem acompanhado pessoas homossexuais e transgênero, lembrando o caso de Diego, e exortou: "as pessoas devem ser acompanhadas como as acompanha Jesus. [...] em cada caso, acolhê-lo, acompanhálo, estudá-lo, discernir e integrá-lo. Isto é o que Jesus faria hoje" (FRANCISCO, 2016).

\section{Conclusão}

A renovação pastoral empreendida pelo papa Francisco contagiou a Igreja Católica. O seu prestígio é considerável dentro e fora do mundo católico. O seu exemplo, pregação e medidas no governo da instituição abrem caminhos promissores. Mas convém que este tempo favorável, um verdadeiro kairós, não seja desperdiçado. As estruturas caducas incapazes de acolhimento também têm formas mentais resistentes e uma forte inércia, que podem entrincheirar a instituição eclesial numa atitude defensiva, longe das periferias existenciais, do drama das pessoas e da compreensão do seu ponto de vista. Oxalá a alegria do amor vivido nas famílias possa sempre se ampliar, alcançando outras configurações familiares, com a colaboração e o júbilo da Igreja.

\section{Para refletir}

1. Como se pode ajudar os que vivem em diferentes configurações familiares em sua devida integração na sociedade e na lgreja?

2. Como abrir o coração aos que vivem nas mais variadas periferias existenciais, especialmente os LGBT?

\section{Bibliografia:}

AL: FRANCISCO. Exortação pós-sinodal Amoris Laetitia. Roma, 2016. Disponível em: $<$ w2.vatican.va $>$. Acesso em: 9 set 2017.

BUTLER, Judith. "La invención de la palabra" (entrevista). Pagina 12, 8 mai. 2009. Disponível em: <www.pagina12.com.ar> . Acesso em: 15 fev. 2018.

Catecismo da Igreja Católica. Roma, 1992. Disponível em: <www.vatican.va $>$. Acesso em: 15 fev. 2018. 
CEF (CONFÉRENCE DES ÉVÊQUES DE FRANCE). Elargir le mariage aux personnes de même sexe? Ouvrons le débat! Paris, 2012. Disponível em: $<$ www.eglise.catholique.fr $>$. Acesso em: 15 fev. 2018.

CNBB (CONFERÊNCIA NACIONAL DOS BISPOS DO BRASIL). Comunidade de comunidades: uma nova paróquia. Brasília, Edições CNBB, 2014.

"Difesa dei diritti e ideologia". L'Osservatore Romano, 19 dez. 2008. Disponível em: $<$ tuespetrus.wordpress.com>. Acesso em: 15 fev. 2018.

FRANCISCO. Solenidade de pentecostes. Santa missa com os movimentos eclesiais. Homilia. Roma, 19 mai. 2013a. Disponível em: <w2.vatican.va $>$. Acesso em: 15 fev. 2018.

Encontro do santo padre com os jornalistas durante o voo de regresso do Brasil. 28 jun. 2013b. Disponível em: <w2.vatican.va $>$. Acesso em: 15 fev. 2018.

. "Entrevista exclusiva do papa Francisco às revistas dos jesuítas". Brotéria, 19 ago. 2013c. Disponível em: <www.broteria.pt>. Acesso em: 15 fev. 2018.

. Conferência de imprensa do santo padre durante o voo Baku-Roma. 2 out. 2016. Disponível em: <w2.vatican.va $>$. Acesso em: 15 fev. 2018.

GS: CONCÍLIO VATICANO II. Constituição pastoral gaudium et spes sobre a Igreja no mundo actual. Roma,1965. Disponível em: <www.vatican.va $>$. Acesso em: 15 fev. 2018.

Intervenção do representante da Santa Sé. 18 dez. 2008. Disponível em: <www.vatican.va $>$. Acesso em: 15 fev. 2018.

JESUS, Jaqueline G. Orientações sobre identidade de gênero: conceitos e termos. Brasília, 2012. Disponível em: <www.sertao.ufg.br>. Acesso em: 15 fev. 2018.

HERCULANO-HOUZEL, Suzana. "O cérebro homossexual". Mente \& cérebro, №165, 2006, p. 46-51.

HERNÁNDEZ, Ana. "El bendito encuentro entre Francisco y Diego". Hoy, 26 jan. 2015. Disponível em: <www.hoy.es>. Acesso em: 15 fev. 2018.

LIMA, Luís. Estudos de gênero versus ideologia: desafios da teologia. Mandrágora, v.21. n. 2, 2015, p. 89-112. Disponível em: <www.metodista.br>. Acesso em: 15 fev. 2018.

PIANA, Giannino. "Sexo e gênero: para além da alternativa". Boletim eletrônico IHU, 16 jul. 2014. Disponível em: <www.ihu.unisinos.br>. Acesso em: 15 fev. 2018.

Resolução no 11, de 18 dez. 2014. Diário oficial da união, 12 mar. 2015, p. 2. Disponível: $<$ www.sdh.gov.br>. Acesso em: 15 fev. 2018. 